\title{
Fine-grained and coarse-grained Paleogene sublacustrine fan systems in Fushan Depression, Beibuwan Basin, South China Sea: implications for sedimentary characteristics and depositional processes
}

\author{
Songqi Pan ${ }^{1,2} \cdot$ Hua Wang ${ }^{3} \cdot$ Zhi Yang $^{2} \cdot$ Entao Liu $^{3}$. \\ Siding $\mathrm{Jin}^{4} \cdot$ Chuanyan Huang ${ }^{3}$ Dapeng $\mathrm{Gao}^{5}$
}

Received: 19 January 2016/Accepted: 7 September 2016/Published online: 15 September 2016

(C) Saudi Society for Geosciences 2016

\begin{abstract}
The Fushan Depression is a hydrocarbon-bearing half-graben rift sub-basin located in the southeast of the Beibuwan Basin, South China Sea. The sublacustrine fan systems in the Paleogene Liushagang Formation have recently become important targets in this depression, while the depositional process and detailed characterization of these systems are little known. Analysis of drilled cores, wire-line logs, and 3-D seismic survey suggest that the Fushan Depression develops two different types of sublacustrine fan systems. The fine-grained sublacustrine fan system located in the western area is mainly composed of fine- to medium-grained light gray sandstones interbedded with layers of silt-rich shales. This kind of sediment slumped from the distal bar of the delta front due to high sediment pore pressures at the slope edge as well as the activity of the Meitai Fault. By contrast, the coarse-
\end{abstract}

Songqi Pan

pansongqi@pku.edu.cn

Zhi Yang

yangzhi2009@petrochina.com.cn

1 School of Earth and Space Sciences, Peking University, Yiheyuan Road 5, Haidian District, Beijing 100871, China

2 Research Institute of Petroleum Exploration and Development, PetroChina, Beijing 100083, China

3 Faulty of Earth Resources, China University of Geosciences, Wuhan 430074, China

4 College of Energy Resources, Chengdu University of Technology, Chengdu 610059, China

5 Institute of Mechanics, Chinese Academy of Sciences, Beijing 100190, China grained sublacustrine fan system formed in the eastern area is characterized by medium to coarse gray sandstones and conglomerates with the development of various deformed lenticular beddings, deformed pillow structures, and micro-faults. Further study suggests that its sedimentation process is closely related to the geomorphology of flexure slope-break belt. The slope changed abruptly from $3^{\circ} \sim 5^{\circ}$ to $7^{\circ} \sim 9^{\circ}$ across the flexure slope point, increasing the accommodation space under the flexure belt. The coarse-grained sublacustrine fan formed when coarse-grained sediment spillover the slope-break toward the increased accommodation space. As the reservoir quality of these sublacustrine fan systems is well controlled by the sedimentary characteristics and sedimentation processes, our results should be of great significance for the development of future exploration.

Keywords Sublacustrine fan systems $\cdot$ Paleogene Liushagang Formation $\cdot$ Sedimentary characteristics .

Paleogeomorphology

\section{Introduction}

As an important type of lithological hydrocarbon reservoirs, the sublacustrine fan systems with good source-reservoir-seal combination are important exploration targets worldwide (Sotak et al. 2001; Weimer and Link 1991). They are principally the result of exploration for the discovery of large hydrocarbon accumulations in the stratigraphic traps. They are also known as submarine fans if they are formed in a marine setting (Bouma 2000; Bouma et al. 1985), initially discovered in the California Borderland (Normark 1970) and in Piedmont basins in Europe (Mutti and Ricci Lucchi 1972). The 
sublacustrine fan systems are basically formed in passive margin settings (Stelting et al. 2000), e.g., Amazon Fan in Brazil (Damuth and Kumar 1975), Mississippi Fan in Gulf of Mexico (Moore et al. 1978), West Africa, and North Sea, and usually deposited in the basin margins. The sedimentary architecture and geographical features of the sublacustrine fan systems are very useful in basin analysis, as they record the tectonic evolution and the sedimentary processes during the formation of these sediments (Benvenuti 2003; Leeder et al. 2002; Mata and Bottjer 2013; Rajchl et al. 2008).

Sedimentary characterization of sublacustrine fans plays a crucial role in controlling reservoir formation and hydrocarbon accumulation (Bellaiche et al. 1994; Chen et al. 2009; Dasgupta 2002). A clear understanding of sedimentary characteristics, facies relationships, tectonic responses, and reservoir qualities is of importance for exploring and exploiting this kind of reservoir efficiently. Although there is a wealth of literature about the sedimentology of the submarine fan systems, the characteristics of the sublacustrine ones differ widely from common marine norms. Sedimentary models for sublacustrine fans in rift basins have been well studied in previous work (Chen et al. 2010; Dasgupta 2002; Liu et al. 2014; Nelson et al. 1999), but little attention has been paid to explain the controls of paleogeomorphology and slope types on sedimentary characteristics, especially within finegrained and coarse-grained sublacustrine fan systems. Moreover, with an increasing demand on petroleum resources in China, the exploration focus has been recently shifted from the petroleum accumulation in the structural traps to that in the stratigraphic traps in the Fushan Depression, since new structural traps are increasingly hard to find. Many scholars have laid great efforts on the Paleogene petroleum system in the Fushan Depression. Liu et al. (2003a, b) have characterized the petrologic composition and geologic background of the Paleogene sublacustrine fan. In order to better understand the sedimentation of the Liushagang Formation and the stack pattern of stratigraphic combination, Li et al. (2014) and Ma et al. (2012) has deciphered the sequence stratigraphy of the Paleogene sedimentary package based on four unconformity-bounded basin phases. Other issues, geochemistry, seismic geology, and petroleum system for example, have also been well studied by many researchers (Chen et al. 2015; Li and Wang 2015; Li et al. 2007; Li et al. 2008b; Zhang et al. 2012).

Liu et al. (2014) reported a detailed work of sedimentation and tectonic setting of the Paleogene sublacustrine fans in the Fushan Depression. They identified two sublacustrine fans in the first member of the Paleogene Liushagang Formation and concluded that these two fan systems were controlled by the multi-level step-fault belt in the west and the flexure slope-break belt in the east. As an expansion of the work presented by Jin et al. (2014), Liu et al. (2014), and Liu et al. (2015), this study focuses on two sublacustrine fan systems deposited in the first and second members of the Paleogene Liushagang Formation, and aims to decipher the architecture of these two different sublacustrine fan systems as well as the controlling factors responsible for their depositional processes. The authors attempt to provide a well-documented example to explain their occurrence in spatial scale and the depositional model, which may be applicable to the exploration and development of newly discovered sublacustrine fan reservoirs in other similar depressions.

\section{Geologic setting}

The Fushan Depression, located in the Qiongzhou Strait northward and on the Hainan High southward (Fig. 1a), is a "dustpan-like" half-graben rift sub-basin belonging to the Meso-Cenozoic intraplate rift basin (Beibuwan Basin) with a covering area of approximately $2920 \mathrm{~km}^{2}$ (Liu et al. 2014; Shi et al. 2007). The depression is bounded by the Lin'gao Fault, the Anding Fault, and the Changliu Fault in the northwest, south, and northeast, respectively. A unique "double-layer structure" was identified in the depression as it represents two kinds of fault systems, i.e., a deeper antithetic, south-dipping fault system and a shallower north-dipping fault system (Lin et al. 2015; Liu et al. 2012; Luo and Pang 2008; Ma et al. 2012) (Fig. 1c). The transfer zone, formed in the central region, separated the depression into two sags, i.e., the Huangtong Sag in the west and the Bailian Sag in the east (Liu et al. 2012) (Fig. 1b). The depression is mainly fed by sediments of braided river from the southern margin (Li et al. 2008a; Liu et al. 2014).

The structure framework of the Fushan Depression owes much of its character to regional tectonic features of the Beibuwan Basin. The basin lies along the southeast margin of the Eurasian Plate, and is adjacent to plate boundaries of the Pacific Plate and the Indian Plate (Jin et al. 2014). The history of the basin was controlled by the combined tectonic evolution of these three plate margins, which can be divided into three major tectonic events: (a) the late Mesozoic Shenhu Movement initiates the rift of the plate and the formation of the Beibuwan Basin; (b) the early Paleogene Qiongzhu Movement is of great importance in shaping the outline of the basin and comprises three rifting episodes; (c) from late Paleogene to Neogene, the Nanhai Movement gives rise to a transition from terrestrial to marine environment resulting in marine basin (Gong 1997; Li et al. 2008c; Qiu and Gong 1999) (Fig. 2).

A sequence stratigraphic technique introduced by Vail et al. (1977) was applied to assess spatial and temporal 


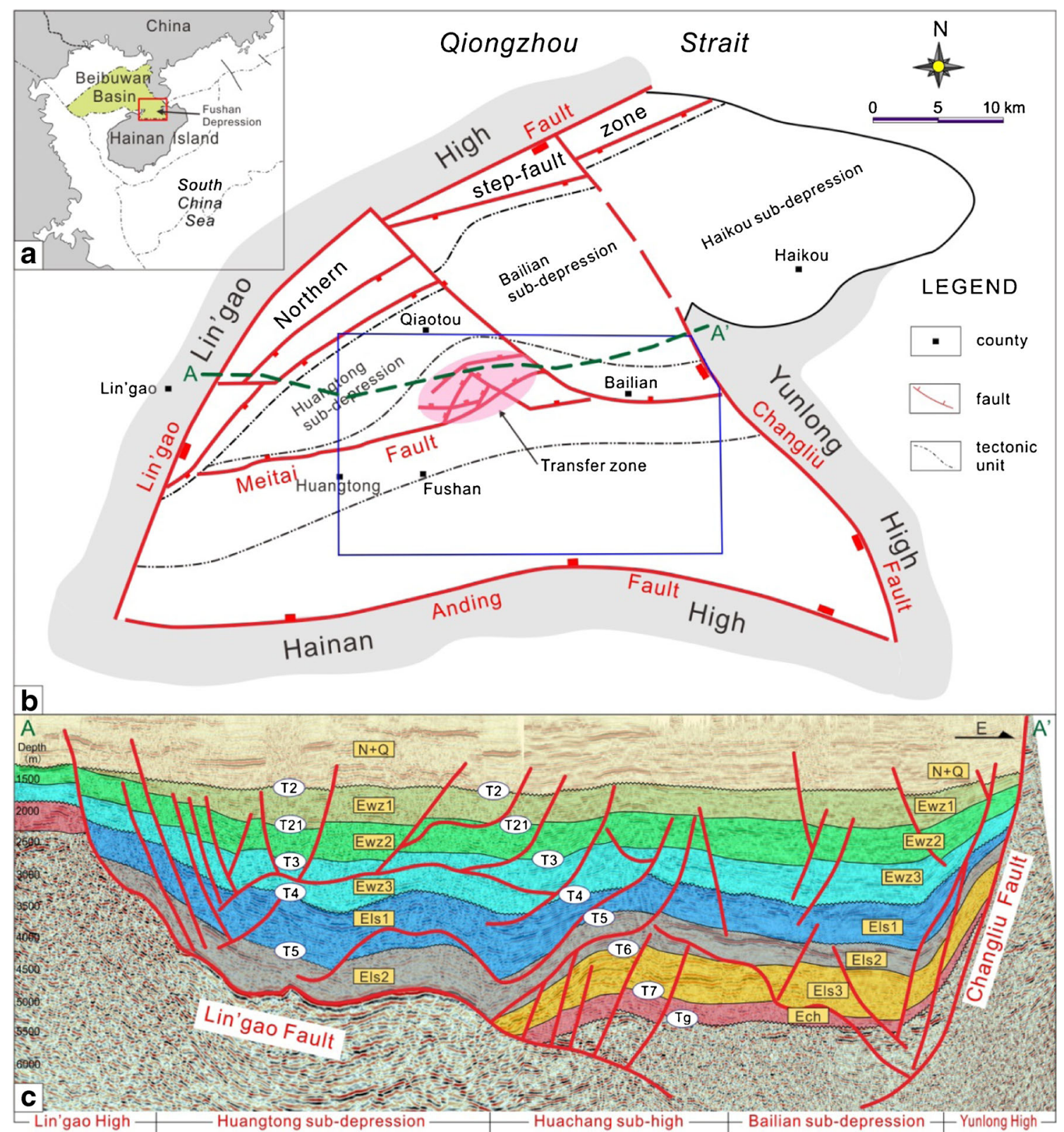

Fig. 1 Schematic map of Fushan Depression showing its location (a) and tectonic units (b), as well as a seismic cross section AA' (c) showing that the Fushan Depression is composed of Huangtong sub-depression,
Huachang sub-high, and Bailian sub-depression from the west to the east. The blue rectangle in $\mathbf{b}$ represents the research area in this study stratigraphic patterns in response to base level changes. The studied Paleogene Liushagang Formation can be divided into three third-order sequences named SQEls 1 , $\mathrm{SQE} l s 2$, and SQEls3 from top to the base, bounded by sequence boundaries $\mathrm{T}_{4}, \mathrm{~T}_{5}, \mathrm{~T}_{6}$, and $\mathrm{T}_{7}$ (Fig. 2). $\mathrm{T}_{4}$ and $\mathrm{T}_{5}$ are two second-order sequence boundaries, which represent abrupt changes in lithology and depositional facies, and are commonly angular unconformities that often correspond to low-frequency, strong-amplitude, and moderate-continuity seismic reflectors. At the bottom of $\mathrm{SQE} l s 2, \mathrm{~T}_{6}$ is a continuous seismic surface with moderate frequency and reflection amplitude and indicates a beginning period of drastic subsidence associated with an increasing extension of the lacustrine basin (Jin et al. 2014; Ma et al. 2012; Vail et al. 1977). Otherwise, $\mathrm{T}_{7}$ boundary is a seismic surface characterized by moderate to low frequency and moderate reflection amplitude. Also, the seismic reflection terminations such as truncation, toplap, onlap, and downlap can be found as good indicators for the above sequence boundaries (Catuneanu 2006; Vail et al. 1977; Weimer and Link 1991). Furthermore, in each third-order sequence, three systems tracts can be identified by the integration of stratal stacking patterns, types of bounding surfaces, and base level changes, i.e., 


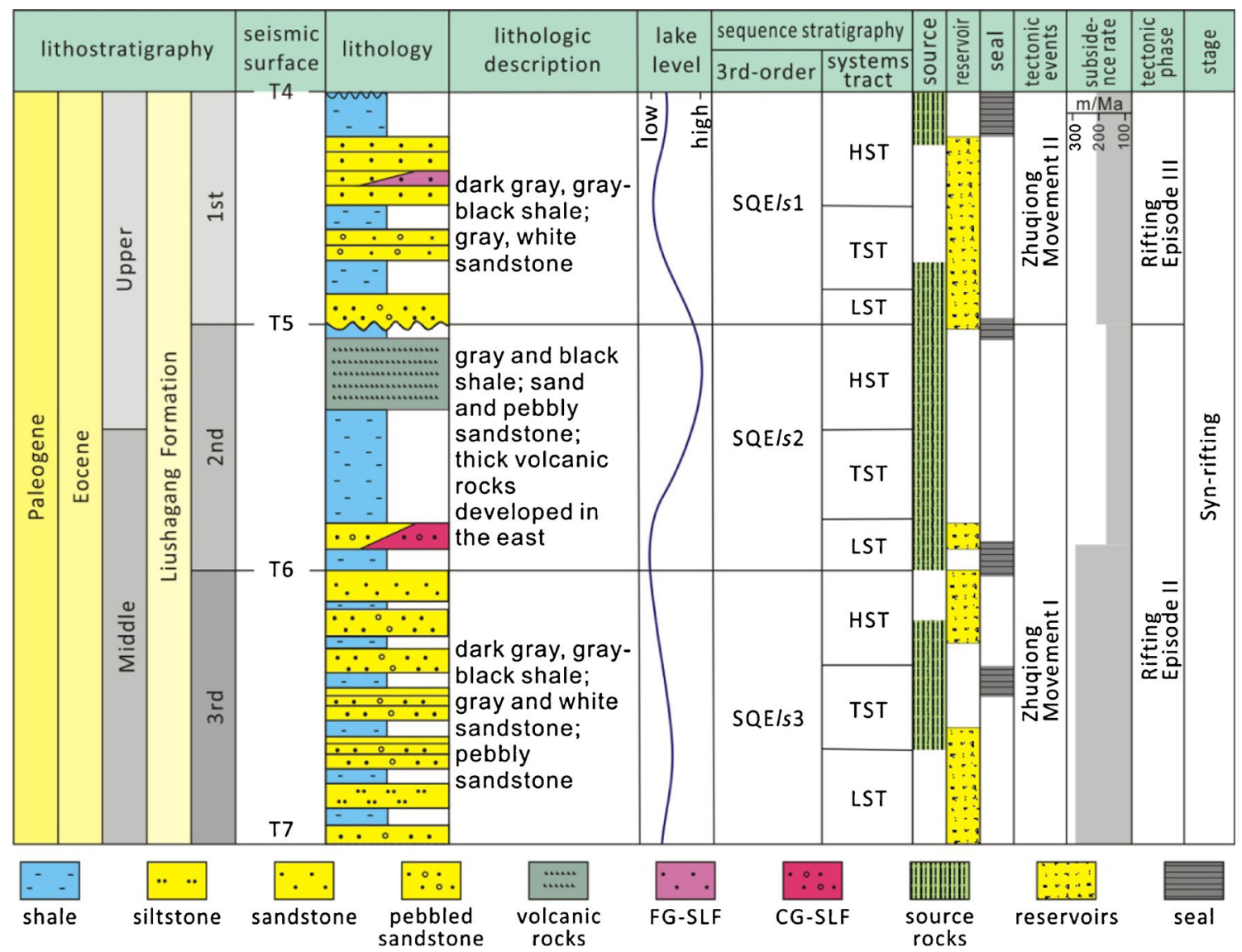

Fig. 2 Sedimentary sequence and stratigraphic framework of the Paleogene Liushagang Formation showing source-reservoir-seal combination and tectonic evolution history. Modified from Jin et al. (2014) and Liu et al. (2014)

lowstand systems tract (LST), transgressive systems tract (TST), and highstand systems tract (HST) (Jin et al. 2014; Vail and Posamentier 1988).

\section{Materials and methods}

The basic data and materials in the study, collected from the Fushan Oilfield Company of PetroChina, include around 230 drilled cores and corresponding wire-line logs, as well as a 3-D seismic survey covering an area of approximately $827 \mathrm{~km}^{2}$. Over $100 \mathrm{~m}$ of cores and corresponding lithological and logging interpretation, including natural gamma (GR), true resistivity (RT), and spontaneous potential (SP), were used to rebuild the depositional facies and to identify fine- and coarse-grained sublacustrine fan systems (FG-SLF and CG-SLF) at the western and eastern areas, respectively, of the Paleogene Liushagang Formation. Thirteen wells, located within the areas of the western FG-SLF (wells W1-W6) and the eastern CG-SLF (wells E1-E7), were selected for depositional characterization.

The seismic profiles were used to track facies distribution range, especially in areas lacking wells. The 3-D seismic survey with the peak frequency of $\sim 35 \mathrm{~Hz}$ collected from local petroleum industry covers a region of approximately
$2000 \mathrm{~km}^{2}$ in the southern part of the Fushan Depression. In addition, 3-D seismic data was also used for structural characterization. The seismic data has been calibrated with wells data to identify seismic reflectors and lithological markers by velocity information from check-shots. Finally, this study presented the reconstruction of the depositional processes and established a proper depositional model for a general understanding of FG-SLF and CG-SLF.

Fig. 3 Panel diagram showing depositional facies and provenance of the western FG-SLF system of SQEls1, associated with selected wells and drilled cores with typical sedimentary structures. Collected depth (m) for each sample can be found on each photo. a Gray pebbly greywacke with deformed muddy debris; b black shale with deformed sandy debris; $\mathbf{c}$ gray pebbly greywacke with grain size up to $10 \mathrm{~mm}$; d approximately 2-m-long drilled core showing a thin black shale interbedded within gray fine sandstone; e light brown fine sandstone with deformed muddy lenticular beddings; $\mathbf{f}$ siltstone with thin deformed layers of pebbly grains; $\mathbf{g}$ brown siltstone with thin layers of pebbly sandstone and deformed shale; $\mathbf{h}$ approximately $2-\mathrm{m}$-long drilled core showing upper gray sandstones and lower black shales; i greywacke with medium-sized sand grains; $\mathbf{j}$ siltstone with deformed muddy debris and contorted muddy layer; $\mathbf{k}$ siltstone containing a deformed pebbly lenticular bedding with grain size up to $5 \mathrm{~mm}$; l siltstone with muddy debris; $\mathbf{m}$ fine sandstone with small-scale deformed muddy lenticular beddings; $\boldsymbol{n}$ black sandstone with muddy lenticular bedding 

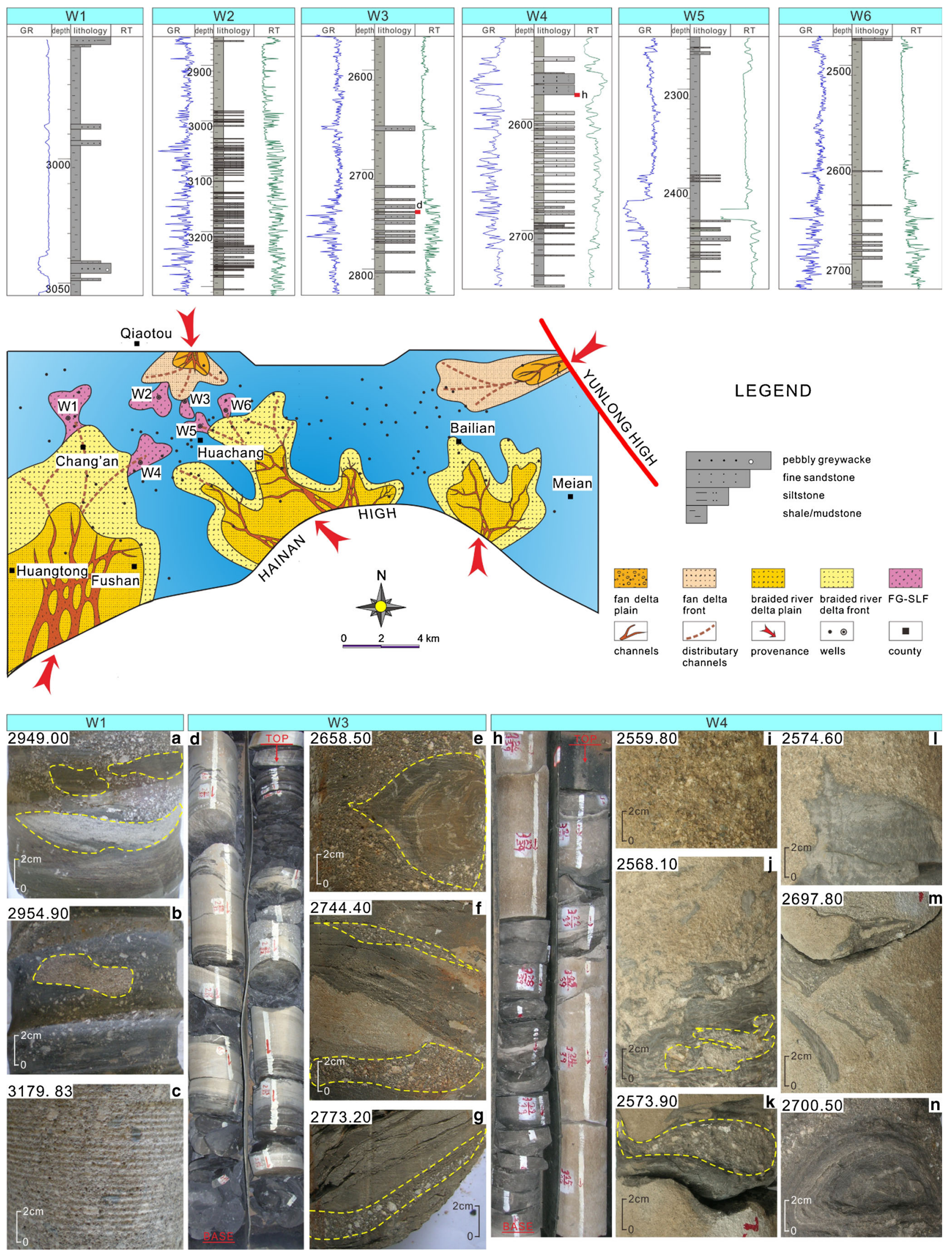


\section{Results}

\section{Description and interpretation of core samples}

The sedimentary succession of the Paleogene Liushagang Formation in the Fushan Depression is characterized by the repetition of sandstone-dominated and siltstonedominated rocks at the background of dark gray mudstone (Figs. 3 and 4). In western areas, the succession is characterized by low sand-to-shale ratio. It is commonly dominated by light gray sandstones with fine- to mediumsized grains associated with pebbly conglomerates (Fig. 3c, d, h) and muddy debris (Fig. 3a, i, 1). Sometimes, siltstone-dominated debris is embedded in black shale (Fig. 3b) or muddy debris is wrapped in siltstone (Fig. 3k). Thin layers of pebbly grains ranging from 10 to $20 \mathrm{~mm}$ are often embedded in shale or siltstone (Fig. 3f, g, j). In addition, some small-scaled muddy lenticular beddings up to $30 \mathrm{~mm}$ (Fig. $3 \mathrm{e}, \mathrm{m}, \mathrm{n}$ ) can be observed in drilling samples. Various deformed structures can be observed in core samples from FG-SLF. For example, deformed sandy lenticular beddings are embedded in black shale (Fig. 3b) or light gray siltstones (Fig. 3f, g, k) and deformed muddy lenticular beddings also appear in sandstones (Fig. 3a, e, m, n). Moreover, contorted shales present in light gray fine-grained sandstones as well (Fig. 3f, j). All the above observations are typical sedimentary features of a fine-grained sublacustrine fan system (Carroll and Bohacs 1999; Feng et al. 2010; Mattern 2005; Richards et al. 1998; Shanmugam and Moiola 1988).

In contrast, in eastern areas, the succession is characterized by a high net-to-gross percentage of sand-rich sediments (Stelting et al. 2000). Thin sandy or silty shales divide the successive systems (Fig. 4a, f, k). In general, it is made up by medium- or even coarse-grained sandstone with pebbly conglomerates (Fig. 4b, d, e, j, m) and muddy debris (Fig. 4l, n, o). Some black muddy debris with a diameter from 10 to $50 \mathrm{~mm}$ are wrapped in gray coarse sandstones (Fig. 4b, d), whereas some sandy debris are embedded in black shales forming small lenticular beddings (Fig. 4g, i, m, p). Moreover, some micro-faults can be found in core samples as well (Fig. 4c, h). Some deformed structures can be observed in core samples as well. The deformed sandy lenticular beddings, for example, can be found in black shales (Fig. 4g). Typical samples contain deformed slump structures and deformed pillow structures (Fig. 4m, n, o). Deformed thin-bedded shales are embedded in light gray sandstones (Fig. 4j). Other deformed structures, deformed liquefactions for example, are also present in CG-SLF (Fig. 4i, k). It is obvious that the sediments in the eastern sublacustrine fan are much coarser than that in the western one, indicating that in the east area, sediments from the Hainan Uplift experienced a shorter distance transportation. In contrast to the western FG-SLF, the much coarser eastern one can be classified into a CG-SLF.

\section{Spatiotemporal distribution of FG-SLF and CG-SLF}

Figures 3 and 4 show the locations of the FG-SLF and CGSLF in the center of Huangtong sub-depression and Bailian sub-depression, respectively. It should be noticed here that the two sublacustrine fans were formed in the different sedimentary stages, i.e., the FG-SLF corresponding to SQEls 1 , while the CG-SLF formed during the SQEls2 sedimentary period. The main source area of both sublacustrine fans is located in the Hainan High, although the CG-SLF sediments were sourced from the northeastern Yunlong High. These sublacustrine fans, pushed ahead from the delta front and deposited in the deep lake, are divided by the Huachang structural transfer zone, which is located at the center of the Fushan Depression and balances the structural deformation difference between these two sub-depressions (Liu et al. 2012). It should be noticed that this transfer zone is crucial for the sedimentary patterns (Liu et al. 2015), because it was not only the sediment source for the adjacent sub-depressions, but it also can split sediment inputs into two parts and can block and restrict the ongoing routes of sediment.

In addition, in cross sections LC1, LC2, and LC3 (Figs. 5, 6, and 7) the FG-SLF of SQEls 1 and the CGSLF of SQEls 2 show similar vertical and lateral extensions. In the western part in SQEls 1 , the content of mud-rich sediments increases while single thickness of layers decreases gradually toward the deep lake (Fig. 5). Well W2 reveals several typical FG-SLF intervals in the deep lake. These intervals are mainly distributed in the HST and TST of SQE $l s 1$ and are formed by the sliding of unstable and unconsolidated delta front sediments due to abrupt variations in topography (Liu et al. 2014), while

Fig. 4 Panel diagram showing depositional facies and provenance of the eastern CG-SLF system of SQEls2, associated with selected wells and drilled cores with typical sedimentary structures. Collected depth (m) for each sample can be found on each photo. a Approximately 2-m-long drilled core showing a contacting relation between upper brown coarse sandstone and lower siltstone; b light gray pebbly conglomerate with muddy debris up to $50 \mathrm{~mm}$; $\mathbf{c}$ gray laminated siltstone with microfaults; $\mathbf{d}$ light gray coarse sandstone with muddy debris up to $20 \mathrm{~mm}$; e Bouma sequence showing an obvious fining-upward trend from coarse sandstone at the bottom to shale at the top; $\mathbf{f}$ approximately $2-\mathrm{m}$-long drilled core showing light gray coarse sandstone interbedded within black shale; $\mathbf{g}$ black shale with deformed sandy lenticular beddings; $\mathbf{h}$ laminated mudstone with micro-faults; i black shale with deformed lenticular beddings and liquefactions; $\mathbf{j}$ deformed then-bedded muddy layers embedded in light gray sandstone; $\mathbf{k}$ approximately $2-\mathrm{m}$-long drilled core showing a fining-upward trend from light gray coarse sandstone with deformed liquefactions at the bottom to black shale at the top; I gray sandstone with shale laminations and micro-faults; $\mathbf{m}$ medium-grained sandstone with pebbly conglomerates; n, o sandstone with muddy debris; $\mathbf{p}$ sandy debris embedded in gray siltstone 

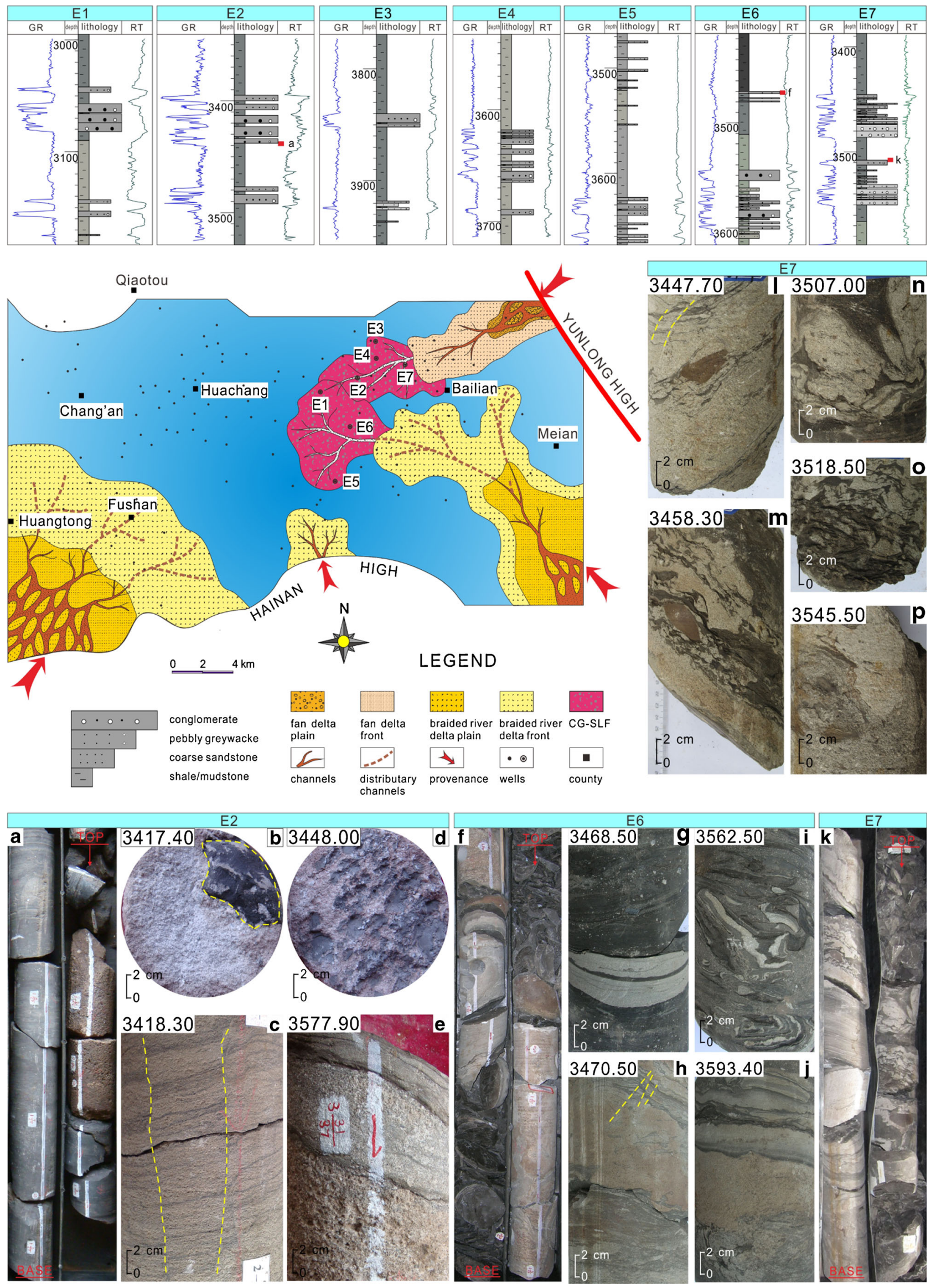


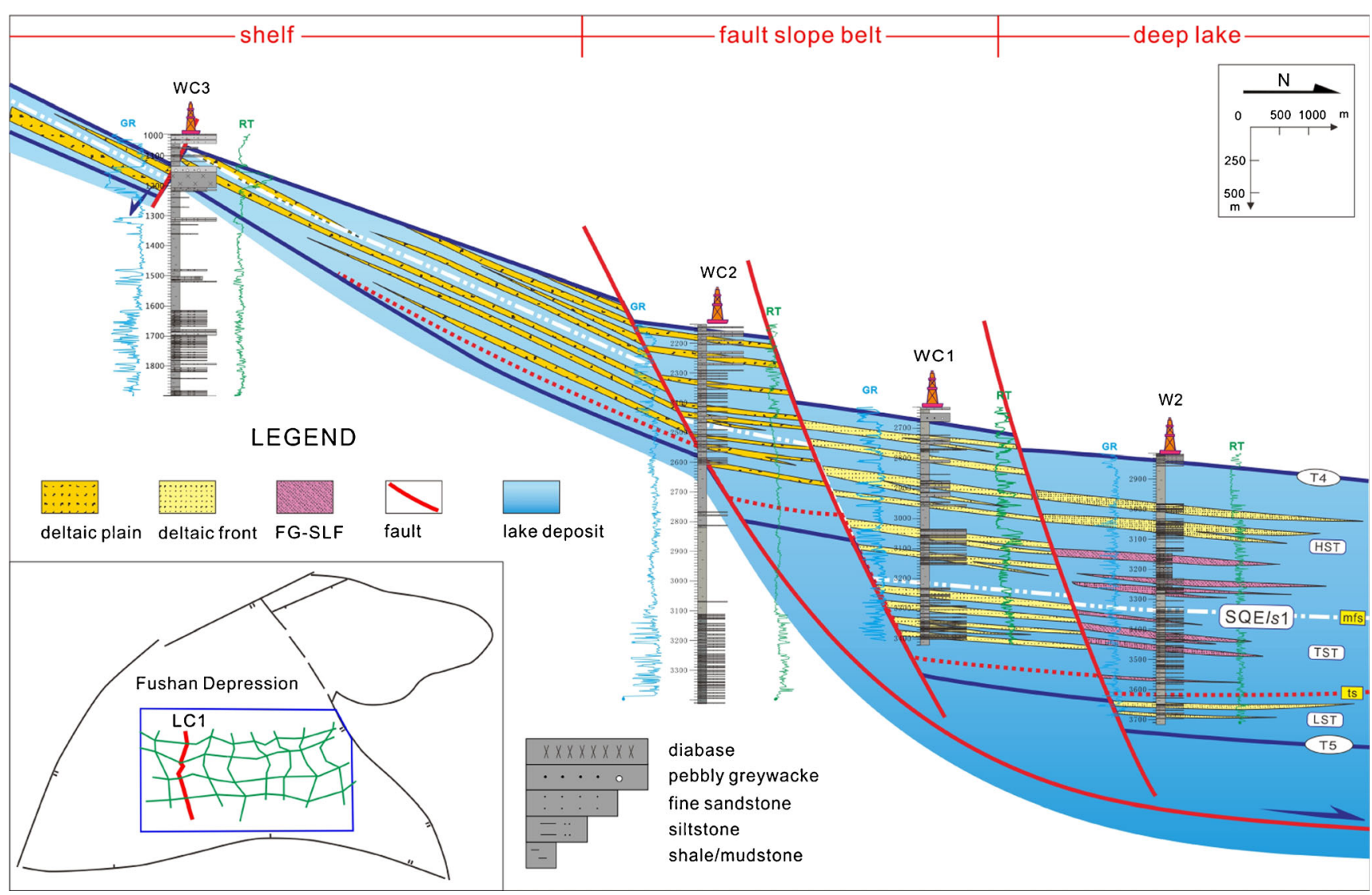

Fig. 5 Borehole correlation cross section LC1 of SQEls 1 in N-S direction showing the lithological and sedimentary characteristics of the FG-SLF in the western area. The FG-SLF can be found in well W2 deposited in deep lake environment

some CG-SLF intervals can be found from the gentle slope-break belt to deep lake in the LST and TST of SQEls2 in the eastern part (Fig. 6). The sediment of delta front progrades toward deep lake gradually. When it exceeds the slope-break belt, the topographical variation and slope gradient changes may make the sublacustrine fans spread on the slope and onto the basin floor. From slope-break belt to deep lake, the gross thickness of shale increases accompanied by more and more thin interbeddings of shale and sandstone.

\section{Discussions}

\section{Paleogeomorphology}

Paleogeomorphology, a science of the buried relief features and of processes which created them (Martin 1966), has been widely used for solving problems connected with exploration for and development of many hydrocarbon accumulations. It usually plays a dominant role in the spatial distribution of sand bodies as well as controls on the patterns of sediment fillings. In this study, a different paleogeomorphology in the western and eastern parts of the Fushan Depression shows their own relief features and influences different sedimentation and provenance inputs to form FG-SLF in the west and CG-SLF in the east. In general, the paleogeomorphology of the Fushan Depression can be divided into two parts - a lowland in the north and a highland in the south - and three parts from west to east as Huangtong sub-depression, Huachang sub-high, and Bailian sub-depression (Fig. 7).

In the west, the paleogeomorphology is dominated by a number of synsedimentary faults which initiates corresponding to SQEls2 in the Meitai Fault slope belt area (Fig. 8a). These faults, extending along the NNE direction to Huachang sub-high eastward and to Lin'gao High westward, are forming a fault slope belt. The surface of the fault slope belt is narrow and steep and is much steeper in the central part than in lateral sides. Some scholars have calculated that the slope angle of faults is $7^{\circ} \sim 12^{\circ}$ (Wang et al. 2014). This fault slope system is also present in SQEls 1 but with a much steeper gradient $\left(11^{\circ} \sim 16^{\circ}\right)$ (Wang et al. 2014). This relief can be divided into a gentle slope area southward and a depression area northward (Fig. 8a) and can explain how the sand bodies expand which will be discussed below.

In contrast, the paleogeomorphology in the eastern area is of great difference from that in the west. Firstly, instead of synsedimentary faults, a flexure slope-break belt is 


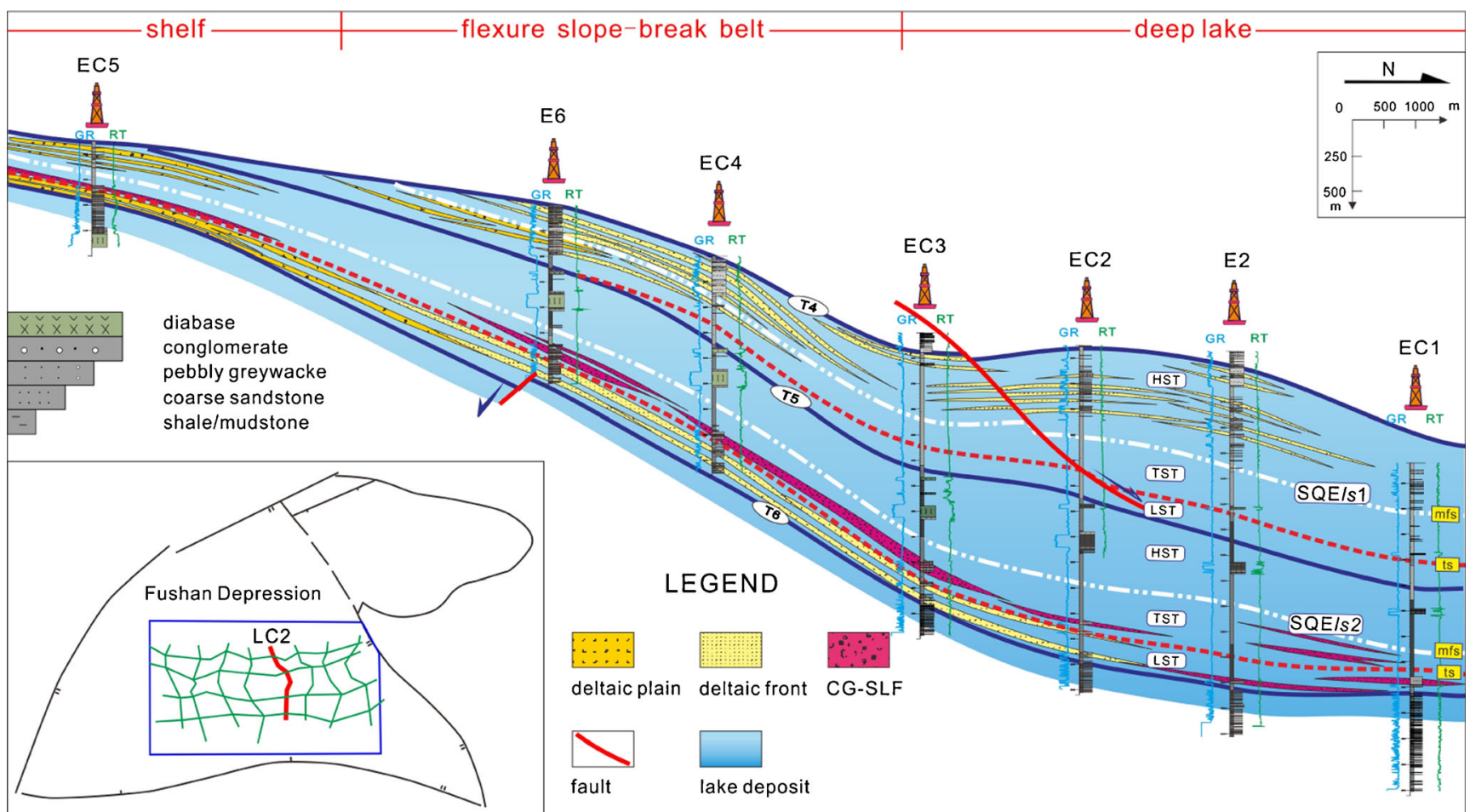

Fig. 6 Borehole correlation cross section LC2 of SQEls 1 and SQEls 2 in $\mathrm{N}-\mathrm{S}$ direction showing the lithological and sedimentary characteristics of the CG-SLF in the eastern area. The CG-SLF can be found in wells EC1,

initially formed in the eastern Bailian sub-depression during the sedimentary period of SQEls 2 and extends to the Huachang High westward and disappears to the Yunlong High eastward (Fig. 8b). With a wide and gentle surface, this slope-break belt has a gradient of $3^{\circ} \sim 5^{\circ}$ calculated from original thickness (Wang et al. 2014). In the sedimentary period of SQEls2, the slope-break belt inherits the spatial distribution but with much steeper gradients ranging from $7^{\circ}$ to $9^{\circ}$. Due to the differentiated paleogeomorphology in the west and east, a CG-SLF was formed under a tectonic background of flexure slope-break belt in the east, which will be discussed below.

\section{Depositional processes and controlling factors}

\section{Sediment source}

Commonly, the sedimentary source supply can be identified by the integration of the occurrence of peripheral river systems, heavy mineral analysis, seismic properties, and regional tectonic evolution (Zou et al. 2013). These materials, however, are lacking and imperfect for this study. Instead, we are trying to determine the source supply by the position and progradation structure of the depositional systems, as well as the rock composition and sediment distribution.
E2, EC2, EC3, EC4, and E6 deposited onto slope and in deep lake environment

There are two stable and inheritably source areas in the Fushan Depression, i.e., the Hainan High in the south and the Yunlong High in the northeast (Figs. 3 and 4). The southern provenance area, expanding largely and upraising increasingly during the period of SQEls3, is accompanied by a gradual rise of the Hainan High. Meanwhile, detrital materials of the terrigenous origin are subject to mechanical and chemical weathering processes due to a change of paleoclimate from warm, humid to hot, arid environment and, accordingly, give rise to a large quantity of debris deriving basinward to form some deltas (Stelting et al. 2000; Zhang et al. 2012). In contrast, the sediments from the Yunlong High provenance area in the northeast can prograde directly to the Bailian Sag to form a fan delta system governed by the Changliu Faults in lateral sides.

\section{Depositional process of the western FG-SLF system}

The integration of paleogeomorphology and sedimentary source supply is responsible for the depositional system distribution in the Huangtong sub-depression (Fig. 8a). The long transport route from the sediment provenance area to the slope and the low-gradient relief on the gentle fault slope belt area lead to a differential deposition of finer sediment discharging basinward, leaving coarser sediments behind (Fig. 5). The $\mathrm{SQE} l s 2$ contains lake sediments developed in a regional 


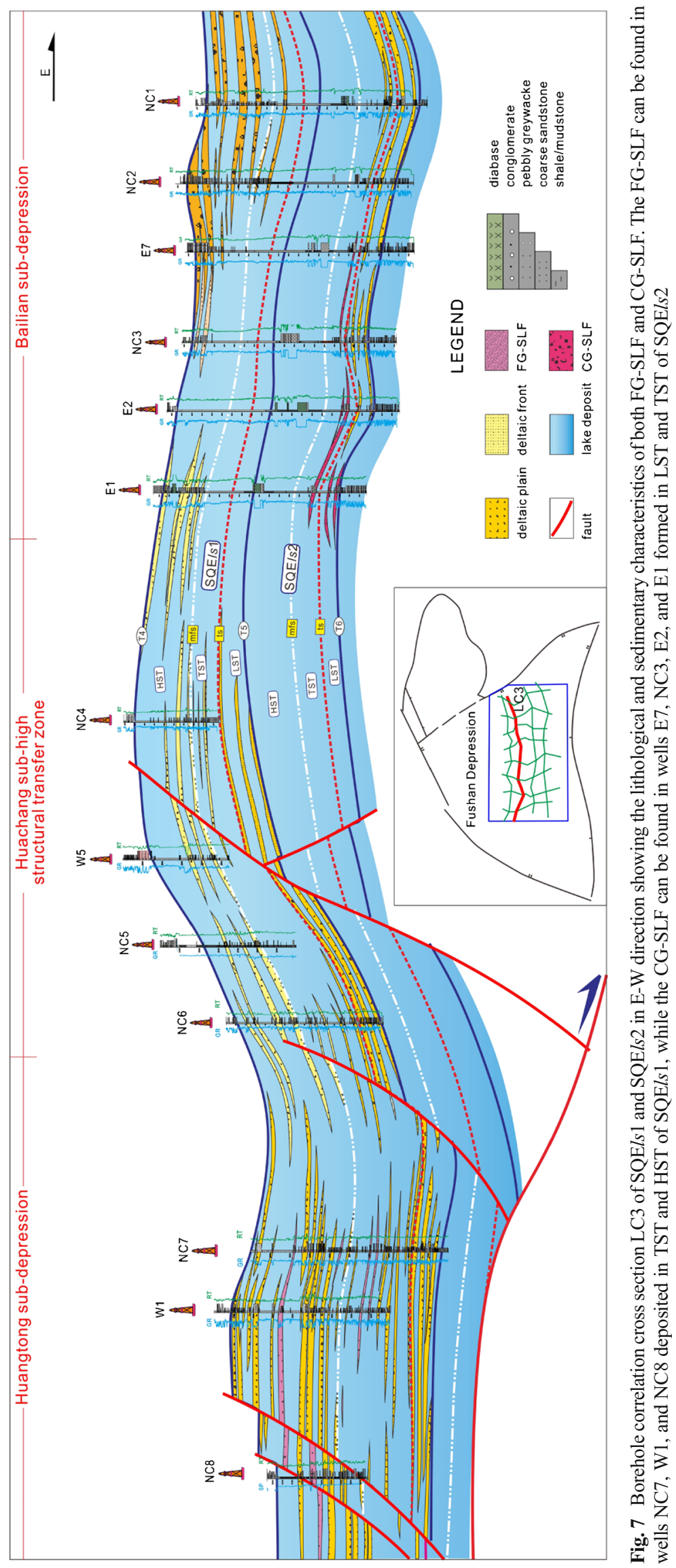


Fig. 8 Paleogeomorphologic diagrams of Fushan Depression showing different features of fault slope belt in the west corresponding to SQEls 1 (a) and flexure slope-break belt in the east corresponding to SQEls2 (b)

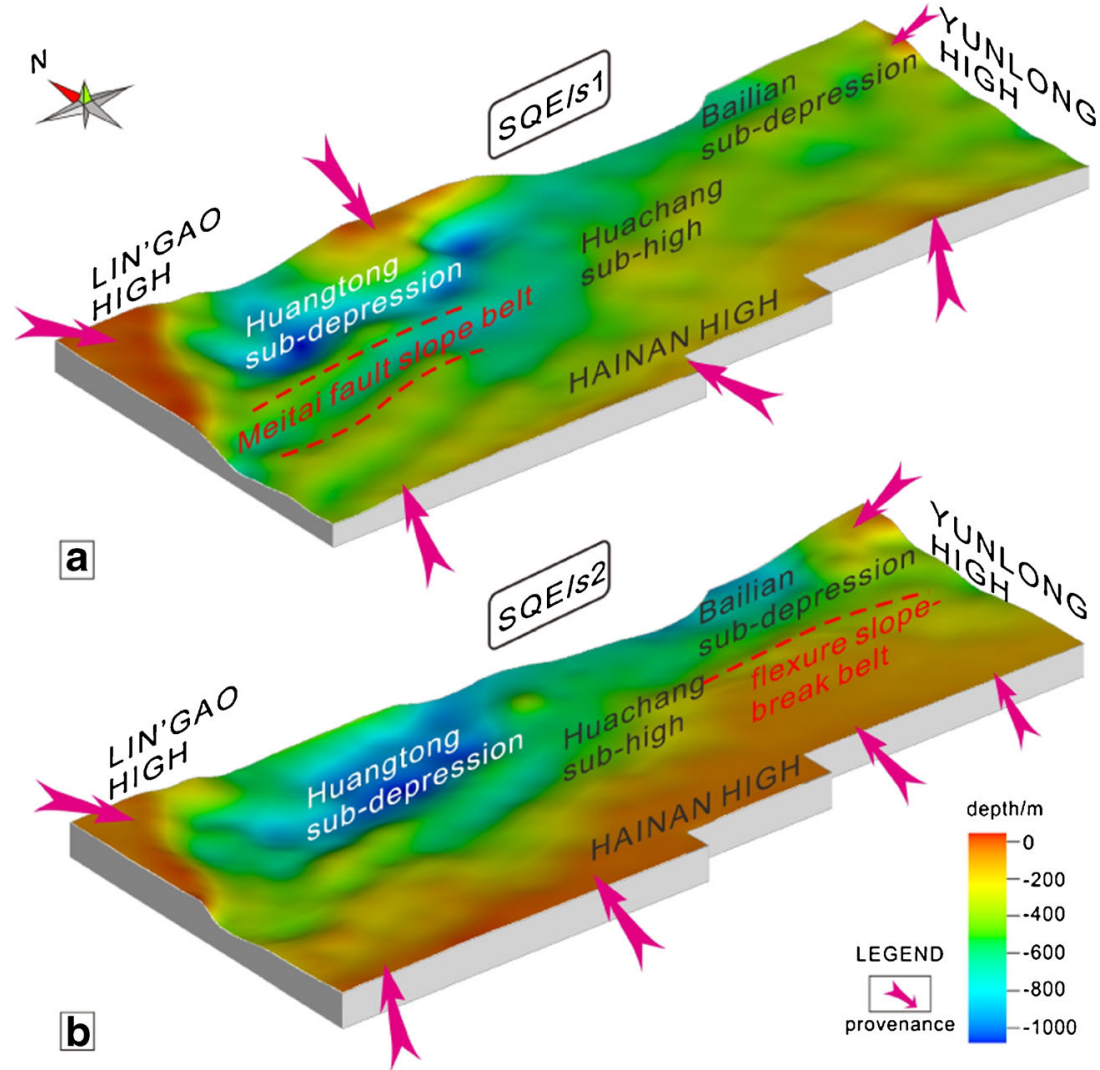

transgressive period, and little sediment is transported from the southern source area, as indicated by the less-developed delta sand bodies. Little sediment supplied from the south in the LST limits the formation of the delta system so that only mud-rich sediments can be found near the fault slope belt. In the TST and HST, however, the rising of lake level results in a
Fig. 9 A conceptual depositional model for two types of sublacustrine fan systems showing distinction of development background, forming mechanism, and sedimentary characterization. The FG-SLF and CG-SLF belong to different sedimentary periods (SQEls1 and SQEls2, respectively) but have been put together to make a correlatable comparison

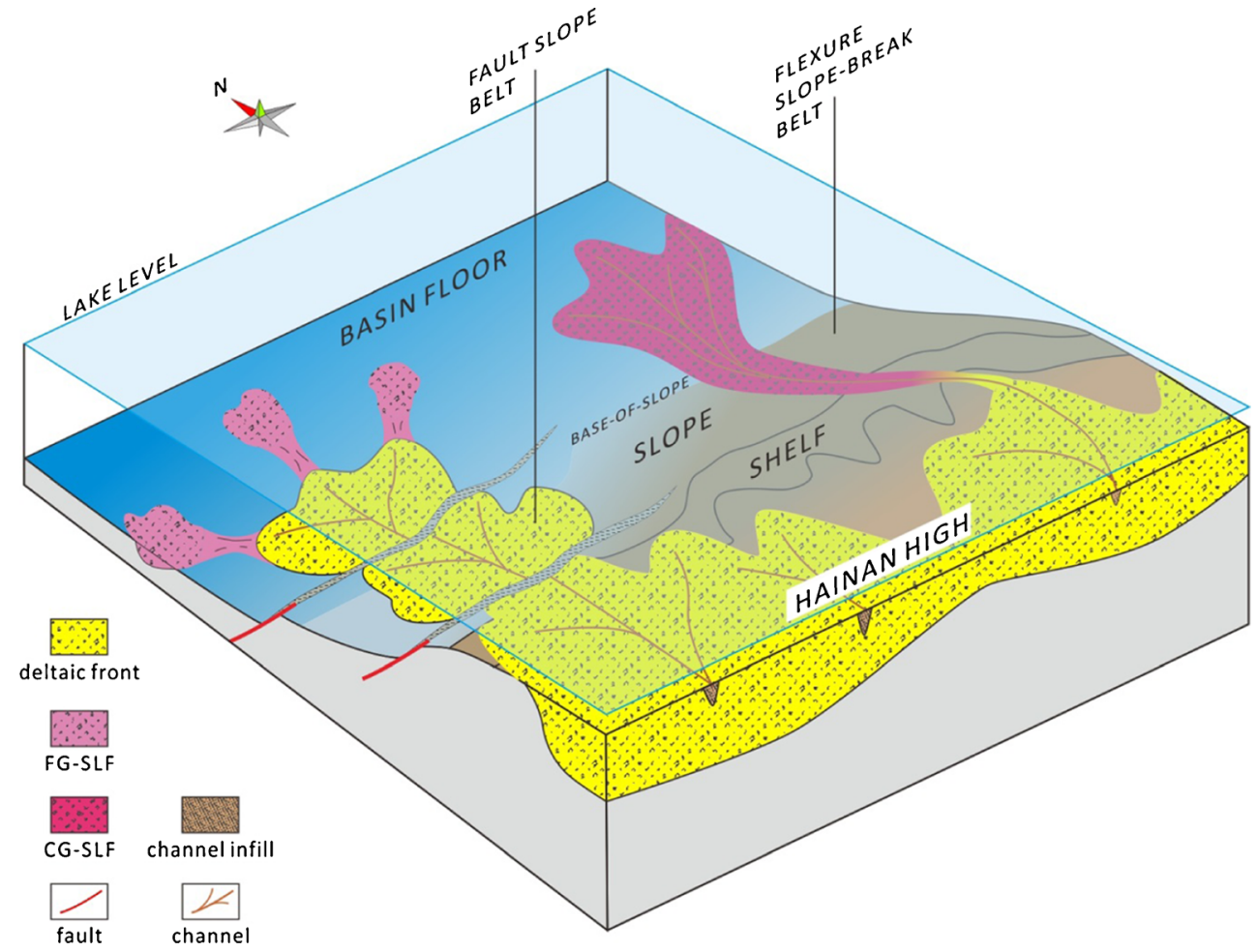


reduction of erosion and confines the occurrence of sublacustrine fans correspondingly. The distributary channels stack up, and the sediments of the slope belt are composed of inter-channel deposits and flood fans. Likewise, the basin floor is covered by a distal bar of the delta front and extensive sheet sands.

In the LST of SQEls1, compared to the LST in SQEls2, although the lake is in the condition of shrinking as well, the sediment derived from Hainan High is enough to compensate the incised valleys on the gentle slope area and allow flow-carried transport runs over the fault slope belt to form a fluvial system (Fig. 3). During TST and HST periods, however, the lake reaches its highest level and starts to fall, and the deltaic distributary channels prograde to the slope-edge area. When fine-grained sediment from the outer area of the delta front encounters a steep slope, an increase of accommodation will make sediment rapidly piled up at the edge of the slope. This rapid accumulation will result in high pore pressures, which will further cause instability and commonly initiate sliding and slumping in the fine-grained delta front sediment. Meanwhile, this slope is the steepest part for the entire transport route, and when the gravity flows with increased velocity reach the base-of-slope zone, a reduction in gradient can trigger initial deposition. Based on an understanding of the underlying sedimentation process, those gravity flow sediments formed along the slope and at the base-of-slope are FG-SLF (Fig. 5).

\section{Depositional process of the eastern CG-SLF system}

Compared to the depositional process of the western FG-SLF system, the formation of the eastern CG-SLF system is of great difference because of its typical paleogeomorphologic features and corresponding flexure slope-break belt (Fig. 8b). In the sedimentary period of SQEls2, the regional lake is expanding in general, but the lake level fluctuations in each systems tract are different (Fig. 7). In the LST, more sediments are available from the Hainan and Yunlong Highs to form a delta system above the slope-break point. Once sediment reaches the flexure slope-break belt, a suddenly changed relief from $3^{\circ} \sim 5^{\circ}$ to $7^{\circ} \sim 9^{\circ}$ associated with the exposure of slope belt makes coarse-grained sediments discharged on the slope and onto the basin floor to form a sublacustrine fan (Fig. 4). The scarcity of very fine-grained sediment indicates that the sediment source is rather close to the slopeline. Therefore, the relatively short distance and time of terrestrial transport reduce the chance for the particle sorting and the unstable mineral separation, and thus, the transport for the sublacustrine fan itself should be defined as non-efficient. Comparatively, in the TST and HST, highstand lake level weakens the dominant role of flexure slop-break belt for governing the CG-SLF formation. Additionally, the weak, intermittent source supply also makes deltaic sand bodies gradually thinning, even ceasing to pile up in the HST, replaced by a thick succession of shale (Fig. 6).

When entering the LST of SQEls1, along with the shrinking of regional lake, the lake level is lower than the flexure slope-break belt, which makes the slope exposed undergoing an intensive erosion and truncation. It is likely that where debris flow encounters an offshoredirected swale, it will gradually deepen that swale into a canyon head. The upper part of the canyon will be filled until instability is reached and sediment repeatedly fills the canyon. When debris flow moves down canyon into the basin across the slope-break belt, the debris flow changes into turbulent flow which makes sediment piled up below the slope-break belt. In the TST and HST periods, the lake level starts to rise and reaches at the highest position and covers the slope to prevent it from erosion. The sublacustrine fan is barely formed, and submerged distributary channels occur above the slope, while the delta front complex covers the slope with shale spreading across the basin floor (Fig. 6).

\section{Depositional model}

Two types of sublacustrine fan systems have been identified in Fushan Depression, including the FG-SLF that deposited along the fault slope belt in the western Huangtong sub-depression and the CG-SLF controlled by a flexure slope-break belt in the eastern Bailian subdepression (Fig. 9). Owing to the spatial and temporal variations in the interaction of influential factors (e.g., tectonics, climate, sediment, and lake level fluctuations), the formation of these sublacustrine fans belongs to different depositional periods, i.e., FG-SLF deposited in the TST and HST of SQEls 1, while the CG-SLF formed in the LST of SQEls2.

Based on the above discussion, it is assumed that the formation of CG-SLF is closely related with the eastern flexure slope-break belt with a relief ranging from $7^{\circ}$ to $9^{\circ}$. The long distance between the slope-break belt and the coastline resulting from lake expanding in SQEls2 as well as extensive sediment supply result in an admixture of muddy debris and pebbly conglomerates fed by distributary channels. The sediments from the CG-SLF are suggestive of rapid facies variations vertically and laterally. As a result, such subtle traps as lithological and stratigraphic reservoirs can be found in the Bailian sub-depression associated with the CG-SLF occurrence.

Although the gradient of the western fault slope belt is steeper than that of the slope-break belt, it does not mean that sediments in the west are coarser than that in the east. On the contrary, the sublacustrine fan is composed of a stack of fine-grained, mud-rich sediment. This is because 
these FG-SLFs are slumps sliding from the delta front which experience a long-distance, efficient transport to make coarser sediments left behind and finer ones pushing ahead. Therefore, the reservoir of the FG-SLF system contains less conglomerates with good physical properties and is in a good condition of source-reservoir-seal association. This is indicative of favorable potential for future exploration and selecting strategy.

\section{Conclusion}

The purpose of this study is to emphasize two kinds of sublacustrine fan systems which are formed in the Fushan Depression during the Paleogene Liushagang Formation.

Based on an integrated study of drilled cores, wire-line logs, and 3-D seismic survey, two types of sublacustrine fan systems have been identified in this study: finegrained sublacustrine fan system and coarse-grained sublacustrine fan system. These sublacustrine fan systems deposited in a deep lake environment and represent different feed patterns, unequal strength of transport, and various sedimentation ways, i.e., a delta-fed FG-SLF vs. a canyon-fed CG-SLF, an efficient sediment transport for FG-SLF vs. a non-efficient CG-SLF, and a sliding-formed FG-SLF vs. a progradational-formed CG-SLF.

These two sublacustrine fans present different sedimentary characteristics. The FG-SLF is a typical fine-grained depositional system which is characterized by structurecontrolled, low-degree admixtures of muddy debris and pebbly greywacke, massive deformed structures, and favorable reservoir potential. In contrast, the CG-SLF is a sand-rich depositional system which is dominated by coarse sandstones interbedded with conglomerates, and more typical structures can be found such as deformed lenticular beddings, deformed pillow structures, and micro-faults. This kind of thin, sandy proximal density underflows is widely developed within the bathyal to abyssal lacustrine mudstone successions.

The paleogeomorphologic occurrences control the formation and distribution of FG-SLF and CG-SLF systems. The fault slope belt has made the deltaic sediments move forward to the distal and deep areas of the basin floor from the southern Hainan High to form FG-SLF systems in the west. In contrast, the deltaic sediments prograde into the deep lake through the gentle slope area to form CG-SLF systems on the basin floor below the flexure slope-break belt. Moreover, high gradients of $7^{\circ} \sim 16^{\circ}$ in the west and low gradients of $3^{\circ} \sim 9^{\circ}$ in the east account for the different depositional processes for forming the FG-SLF and the CG-SLF. These gradient changes are closely associated with different paleogeomorphology.
Acknowledgment We would like to express our appreciation to the Associate Editor Dr. Beatriz Bádenas and two anonymous reviewers for their comments and suggestions, as well as the Editor-in-Chief Dr. Abdullah M. Al-Amri for his help and advice. We appreciate the Typesetting Editor as well for the improvement of the wording and syntax of this article. Our thanks are also extended to the Fushan Oilfield Company of PetroChina for support in material collecting and permission to publish. This study is financially supported by the program of the National Natural Science Foundation of China (Grant No. 41472084). The China Scholarship Council (CSC) is acknowledged as well for financing the first author studying at GFZ German Research Centre for Geosciences.

\section{References}

Bellaiche G, Droz L, Gaullier V, Pautot G (1994) Small submarine fans on the eastern margin of Corsica: sedimentary significance and tectonic implications. Mar Geol 117:177-185. doi:10.1016/0025-3227 (94)90013-2

Benvenuti M (2003) Facies analysis and tectonic significance of lacustrine fan-deltaic successions in the Pliocene-Pleistocene Mugello Basin, Central Italy. Sediment Geol 157:197-234. doi:10.1016 /s0037-0738(02)00234-8

Bouma AH (2000) Fine-grained, mud-rich turbidite systems: model and comparison with coarse-grained, sand-rich systems. Special Publication-SEPM 68:9-20

Bouma AH, Normark WR, Barnes NE (1985) COMFAN: needs and initial results. In: Bouma AH, Normark WR, Barnes NE (eds) Submarine fans and related turbidite systems. Frontiers in sedimentary geology. Springer, New York, pp. 7-11. doi:10.1007/978-14612-5114-9_2

Carroll AR, Bohacs KM (1999) Stratigraphic classification of ancient lakes: balancing tectonic and climatic controls. Geology 27:99-102

Catuneanu O (2006) Principles of sequence stratigraphy. Elsevier

Chen D, Pang X, Jiang Z, Zeng J, Qiu N, Li M (2009) Reservoir characteristics and their effects on hydrocarbon accumulation in lacustrine turbidites in the Jiyang Super-depression, Bohai Bay Basin, China. Mar Pet Geol 26:149-162. doi:10.1016/j.marpetgeo.2008.03.003

Chen G, Wang T, Li L, Li S, Li J (2010) Characteristics of sublacustrine fan in half-graben rift lake basin and its petroleum prospecting: case study on the second member of Tenggeer Formation, Saihantala Sag, Erlian Basin. Petrol Explor Dev 37:63-69

Chen S, Gan H, Shi Y, Zhao Y, Wang X (2015) Geochemical features and geologic significance of source rocks in Fushan Sag, Beibuwan Basin. Petroleum Geology and Recovery Efficiency 22:14-25 (in Chinese with English abstract) doi:10.13673/j.cnki.cn37-1359 /te.2015.01.003

Damuth JE, Kumar N (1975) Amazon cone: morphology, sediments, age, and growth pattern. Geol Soc Am Bull 86:863-878

Dasgupta P (2002) Architecture and facies pattern of a sublacustrine fan, Jharia Basin, India. Sediment Geol 148:373-387. doi:10.1016 /s0037-0738(01)00141-5

Feng Z et al. (2010) Lacustrine turbidite channels and fans in the Mesozoic Songliao Basin, China. Basin Res 22:96-107

Gong ZS (1997) The major oil and gas fields of China offshore. Petroleum Industry Press, Beijing

Jin SD, Wang H, Cao HY, Chen S, Lin ZL, JH Y, Pan SQ (2014) Sedimentation of the Paleogene Liushagang Formation and the response to regional tectonics in the Fushan Sag, Beibuwan Basin, South China Sea. Austrian J Earth Sci 107:112-130

Leeder MR, Collier REL, Aziz LHA, Trout M, Ferentinos G, Papatheodorou G, Lyberis E (2002) Tectono-sedimentary processes along an active marine/lacustrine half-graben margin: Alkyonides 
Gulf, E. Gulf of Corinth, Greece. Basin Res 14:25-41. doi:10.1046 j.1365-2117.2002.00164.x

Li M, Wang T (2015) The progress and application of reservoir geochemistry in hydrocarbon exploration:an example from the Fushan Depression, Beibuwan Basin, South China Sea. Earth Science Frontiers 22:215-222 in Chinese with English abstract

Li M, Wang T, Liu J, Zhang M, Lu H, Ma Q, Gao L (2007) A discussion on hydrocarbon accumulation dating determined by homogenizaton temperature and burial history of fluid inclusions. Oil Gas Geol 28: 151-158 in Chinese with English abstract

Li M, Wang T, Liu J, Zhang M, Lu H, Ma Q, Gao L (2008a) The occurrence of oleananes in the Beibuwan Basin and its application to the study of maturity and oil-source rock correlation. Acta Geologica Sinica-English Edition 82:585-595

Li M, Wang T, Liu J, Zhang M, Lu H, Ma Q, Gao L (2008b) Total alkyl dibenzothiophenes content tracing the filling pathway of condensate reservoir in the Fushan Depression, South China Sea Science in China Series D: Earth. Sciences 51:138-145

Li MJ, Wang TG, Liu J, Lu H, WQ W, Gao LH (2008c) Occurrence and origin of carbon dioxide in the Fushan Depression, Beibuwan Basin, South China Sea. Mar Pet Geol 25:500-513. doi:10.1016/j. marpetgeo.2007.07.007

Li Y, Wang H, Liu E, Liao Y, Lin Z, Ma Q (2014) Distribution regularities and control factors for reservoir formation within sequence stratigraphic framework in Fushan Sag, Beibuwan Basin. Journal of Central South University (Science and Technology) 45:1542-1554 in Chinese with English abstract

Lin Z, Wang H, Li H, Ma Q, Li Y, Zhao S (2015) Genetic mechanism of double-layer structure in Paleogene of Fushan Sag, Beibu Gulf Basin. Earth Science-Journal of China University of Geosciences 40:169 178 . doi:10.3799/dqkx.2015.012in Chinese with English abstract

Liu L, Mo S, Tong Y (2003a) A discussion on the Paleogene sublacustrine fan of Fushan depression in Beibuwan Basin, northern South China Sea. Acta Petrol Mineral 22:138-142 in Chinese with English abstract

Liu L, Tong Y, Ji Y, Kuang H, Lu M (2003b) Sedimentary characteristics and developing background of the sublacustrine fan in the Liushagang Formation of the Fushan Depression, Beibuwan Basin. Petroleum Geology and Experiment 25:110-115 in Chinese with English abstract

Liu E, Wang H, Lin Z, Li Y, Ma Q (2012) Characteristics and hydrocarbon enrichment rules of transfer zone in Fushan Sag, Beibuwan Basin. Journal of Central South University (Science and Technology) 43:3948-3953 in Chinese with English abstract

Liu E, Wang H, Li Y, Zhou W, Leonard ND, Lin Z, Ma Q (2014) Sedimentary characteristics and tectonic setting of sublacustrine fans in a half-graben rift depression, Beibuwan Basin, South China Sea. Mar Pet Geol 52:9-21. doi:10.1016/j.marpetgeo.2014.01.008

Liu E, Wang H, Li Y, Leonard ND, Feng Y, Pan S, Xia C (2015) Relative role of accommodation zones in controlling stratal architectural variability and facies distribution: insights from the Fushan Depression, South China Sea. Mar Pet Geol 68:219-239. doi:10.1016/j. marpetgeo.2015.08.027

Luo Q, Pang X (2008) Reservoir controlling mechanism and petroleum accumulation model for consequent fault and antithetic fault in Fushan Depression of Hainan area. Acta Pet Sin 29:363-367 in Chinese with English abstract

Ma Q, Zhao S, Liao Y, Lin Z (2012) Sequence architectures of Paleogene Liushagang Formation and its significance in Fushan Sag of the Beibuwan Basin. Earth Science-Journal of China University of Geosciences 37:667-678 in Chinese with English abstract

Martin R (1966) Paleogeomorphology and its application to exploration for oil and gas (with examples from western Canada. AAPG Bull $50: 2277-2311$
Mata SA, Bottjer DJ (2013) Facies control on lower Cambrian wrinkle structure development and paleoenvironmental distribution, southern Great Basin, United States. Facies 59:631-651. doi:10.1007 /s10347-012-0331-3

Mattern F (2005) Ancient sand-rich submarine fans: depositional systems, models, identification, and analysis. Earth Sci Rev 70:167202

Moore G, Starke G, Bonham L, Woodbury H (1978) Mississippi Fan, Gulf of Mexico-physiography, stratigraphy, and sedimentation patterns framework, facies, and oil-trapping characteristics of the Upper Continental. Margin 7:155-191

Mutti E, Ricci Lucchi F (1972) Sediments and growth pattern of Navy deep-sea fan, San Clemente Basin, California Borderland:. Jour Geology 80:198-223

Nelson CH, Karabanov EB, Colman SM, Escutia C (1999) Tectonic and sediment supply control of deep rift lake turbidite systems: Lake Baikal, Russia. Geology 27:163-166

Normark WR (1970) Growth patterns of deep-sea fans. AAPG Bull 54: 2170-2195

Qiu ZJ, Gong ZS (1999) Oil exporation in China: offshore. Geological Press and Petroleum Industry Press, Beijing in Chinese

Rajchl M, Ulicny D, Mach K (2008) Interplay between tectonics and compaction in a rift-margin, lacustrine delta system: Miocene of the Eger Graben, Czech Republic. Sedimentology 55:1419-1447. doi:10.1111/j.1365-3091.2008.00951.x

Richards M, Bowman M, Reading H (1998) Submarine-fan systems I: characterization and stratigraphic prediction. Mar Pet Geol 15:689-717

Shanmugam G, Moiola R (1988) Submarine fans: characteristics, models, classification, and reservoir potential. Earth Sci Rev 24: $383-428$

Shi Y, Liu J, Zhang M, Chen D, Ma Q (2007) Experience and understand in oil and gas exploration in Fushan Sag. Hainan Province South China Journal of Seismology 27:57-68 in Chinese with English abstract

Sotak J, Pereszlenyi M, Marschalko R, Milicka J, Starek D (2001) Sedimentology and hydrocarbon habitat of the submarine-fan deposits of the Central Carpathian Paleogene Basin (NE Slovakia. Mar Pet Geol 18:87-114. doi:10.1016/s0264-8172(00)00047-7

Stelting CE, Bouma AH, Stone CG (2000) Fine-grained turbidite systems: overview. In: Bouma AH, Stone CG (eds) AAPG Memoir 72/SEPM Special Publication No. 68. American Association of Petroleum Geologists

Vail PR, Posamentier HW (1988) Principles of sequence stratigraphy. In: Sequences, stratigraphy, sedimentology: surface and subsurface, vol Memoir 15. CSPG Special Publications

Vail PR, Mitchum Jr RM, Thompson III S (1977) Seismic stratigraphy and global changes of sea level. In: Seismic stratigraphy - applications to hydrocarbon exploration, vol Memoir 26. AAPG Special Volumes, pp 49-212

Wang G, Huang C, Liu E, Li Y, Pan S (2014) Characteristics of slopebreaks and its control on sedimentation and hydrocarbon accumulation of Liushagang Formation in gentle slope of South Fushan Sag. Journal of Central South University (Science and Technology) 45: 1531-1541 in Chinese with English abstract

Weimer P, Link MH (1991) Seismic facies and sedimentary processes of submarine fans and turbidite systems. Springer

Zhang J, He J, Gong X, Zhang X, Huang W (2012) Petroleum system, oil and gas migration and accumulation in Fushan Depression, Beibuwan Basin of South China Sea. Marine Geology Frontiers 28:30-37 in Chinese with English abstract

Zou CN et al. (2013) Continuous hydrocarbon accumulation over a large area as a distinguishing characteristic of unconventional petroleum: the Ordos Basin, North-Central China. Earth Sci Rev 126:358-369. doi:10.1016/j.earscirev.2013.08.006 